\title{
BMJ Open Suicide bereavement: piloting a longitudinal study in Australia
}

\author{
Kairi Kõlves, Diego de Leo
}

To cite: Kõlves K, de Leo D. Suicide bereavement: piloting a longitudinal study in Australia. BMJ Open 2018;8:e019504. doi:10.1136/ bmjopen-2017-019504

- Prepublication history for this paper is available online. To view these files, please visit the journal online (http://dx.doi org/10.1136/bmjopen-2017019504).

Received 6 September 2017 Revised 18 December 2017 Accepted 19 December 2017
Check for updates

Australian Institute for Suicide Research and Prevention, World Health Organization Collaborating Centre for Research and Training in Suicide Prevention, Griffith University, Brisbane, Queensland, Australia

Correspondence to

Dr Kairi Kõlves;

k.kolves@griffith.edu.au

\begin{abstract}
Objectives The pilot study were (1) to test the technical and administrative feasibility of a full-scale study, including recruitment process, response and retention rate, questionnaire design for an investigation to improve understanding of the suicide bereavement processes compared with bereavement by sudden deaths and (2) to present the differences and changes in the main outcomes-grief reactions of close relatives exposed to suicide and sudden death over 2 years.

Design A longitudinal prospective study comparing bereavement by suicide to other types of sudden deaths over time (6,12 and 24 months).

Setting Queensland, Australia.

Participants 25 suicide-bereaved and 15 sudden-deathbereaved persons.

Outcome measures Grief reactions (measured with the Grief Experience Questionnaire).

Results The response rate was $52.1 \%$ in the suicide bereaved and $45.5 \%$ in the sudden-death group. There was a small number of dropouts, with the retention rate over $85 \%$ for both groups. Linear mixed modelling for repeated measures showed a significant group effect (higher in suicide bereaved) for total grief, responsibility, rejection and unique reactions. A significant time effect (reduction) was measured for total grief, somatic reactions, general grief reactions and search for explanation. One significant time and group interaction was measured; rejection showed a decline in suicide and an increase in sudden-death bereaved.

Conclusions The pilot study presented the appropriateness of the study methodology. This type of study has implications for counselling and treating people bereaved by suicide and for designing postvention activities.
\end{abstract}

\section{INTRODUCTION}

Suicide has significant human and economic consequences, including profound effects on the people who are left behind. Estimating the number of people left behind (referred to as 'suicide survivors' in the USA) is a challenging task due to the differences in types of exposure to suicide depending on quality and characteristics of the relationship with the deceased, but also age of the deceased. ${ }^{1}$ Cerel et $a t^{2}$ proposed that there is a continuum of suicide 'survivorship' including people exposed, affected and short-term and longterm bereaved. A recent meta-analysis found
Strengths and limitations of this study

- This pilot study is a prospective longitudinal study which enables the analysis of changes and differences in the grief reactions of people bereaved by suicide and sudden death over time.

- The recruitment was conducted systematically using the information obtained from the police forms.

- The pilot study had response and retention rates comparable with similar studies with vulnerable subjects.

- The pilot study is limited by the small sample size and unable to adjust for potential confounding factors (eg, help-seeking).

that prevalence of exposure to suicide was $4.3 \%$ in last year and $21.8 \%$ during lifetime. ${ }^{3}$

Family members, relatives and friends impacted by suicide often experience adverse physical, emotional and social outcomes. ${ }^{4-10}$ People bereaved by suicide, similarly to people bereaved by other types of death, experience common grief reactions such as sadness, loneliness, anger, confusion, depression and anxiety. ${ }^{4-6}$ However, some studies have shown that people bereaved by suicide have higher levels of shame, stigma, responsibility and rejection compared with those bereaved by other types of death, including accidental death. ${ }^{4-6}$ Furthermore, grief reactions are not static; however, only a few studies have observed changes over a longer period of time..$^{7-9}$ Large-scale registry-based studies have also shown higher risk of suicide attempts, suicide and specific mental health disorders, in suicide-bereaved family members compared with the other types of bereavement. $^{410}$ Overall, current findings are limited by significant methodological weaknesses such as biased sampling methods (eg, recruitment from bereavement groups), small sample sizes, recall bias, lack of reliable and valid measuring instruments, absence of follow-up and uncontrolled confounding variables. $^{4-6}$

Research indicates a lack of consensus regarding the definition and scope of a pilot 


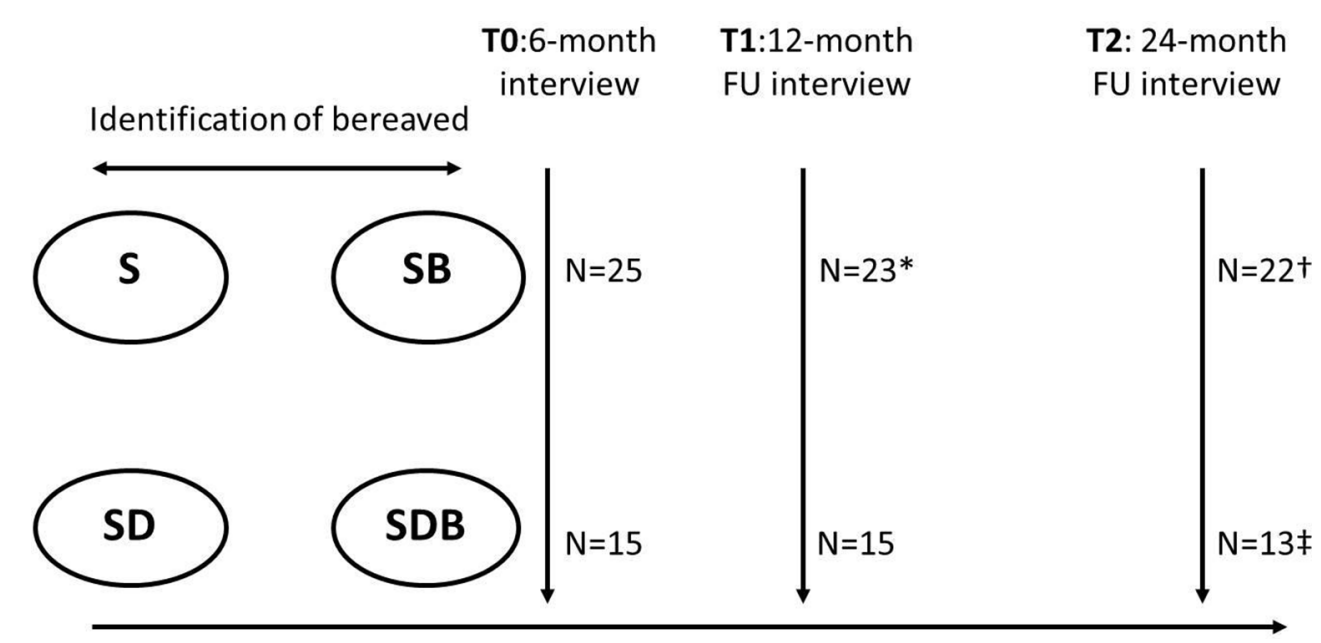

Figure 1 The study design and participant numbers. *Two dropouts-one not contactable; one withdrew. †One dropoutnot contactable. ‡Two dropouts - one not contactable; one died from natural causes. FU, follow-up; S, suicide; SB, suicide bereaved; SD, sudden death; SDB, sudden death bereaved.

study. ${ }^{11-13}$ Nevertheless, the aims of the current pilot study are the following:

1. To test the technical and administrative feasibility of a full-scale study, including recruitment process, response and retention rate, and questionnaire design for an investigation that could create a better understanding of suicide bereavement processes compared with bereavement by sudden deaths.

2. To present preliminary analysis of the differences and changes in the main outcomes-grief reactions (measured with the Grief Experience Questionnaire; GEQ) of close relatives exposed to suicide and sudden death over 2 years.

\section{METHODS}

\section{Study design}

A longitudinal prospective design was used to compare suicide bereavement to bereavement from other types of sudden deaths (figure 1). To identify changes in the bereavement process, the study included three assessment points, 6 (T0), 12 (T1) and 24 months (T2), after the death (deviation of maximum \pm 1 month was allowed). The selection of an appropriate comparison/control group is essential. The rationale to include sudden deaths as comparison/control group was the similarity of the sudden nature of death, which could determine similarities in the grief reactions. The sudden deaths comprised accidents (V01-X59 by ICD-10) ${ }^{14}$ and sudden natural deaths when death occurs within few hours mainly caused by cardiovascular conditions (eg, myocardial infarction and stroke). ${ }^{15}$

Inclusion criteria for the pilot were:

- close relatives-immediate family member ${ }^{\mathrm{i}}$ bereaved by a suicide or sudden death and was contactable $6 \pm 1$ months after death,

${ }^{\mathrm{i}}$ Immediate family member including a spouse, de facto partner, child, parent, grandparent, grandchild, sibling, aunt, uncle, niece and nephew, and immediate in-laws (mother-in-law, father-in-law, brother-in-law and sister-in-law).
- at least 18 years old,

- English speakers,

- death occurred in Queensland, Australia.

\section{Procedure}

People bereaved by suicide were identified through the Queensland Suicide Register (QSR). The QSR contains information regarding contact details of the family members from police forms, along with their permission to be contacted by the Australian Institute for Suicide Research and Prevention for research purposes. Participants for the sudden-death group were identified and recruited by the Queensland Office of State Coroners using the police forms. Family members of consecutive cases of suicides and sudden deaths were approached. Initially, a letter introducing the study, along with the study information sheet and consent form was sent to potential participants. Clinical interviewer(s) contacted participants via phone after the receipt of a consent form, to schedule interviews. All interviews were conducted over the phone. One month before the follow-up interview (12 and 24 months) was due, clinical interviewer(s) sent participants a letter about the interview, which was then followed up by a phone call to schedule an interview time. Thank you letters were sent to all participants after each interview.

The interview followed a semistructured format and included validated psychological scales/questionnaires; the primary instrument was grief reactions, as measured by the GEQ and its subscales. ${ }^{16}$ GEQ is designed to measure two general types of grief reactions: those expected in any bereavement and those potentially unique to suicide. The first group includes somatic reactions and general grief reactions. The second group includes search for explanations, loss of social support, stigmatisation, guilt, responsibility, shame, rejection, self-destructive behaviour and unique reactions (eg, hiding the cause of death) ${ }^{16}$ Each reaction includes five items measured on 5-point Likerttype scale from 1 (never) to 5 (almost always), with total 

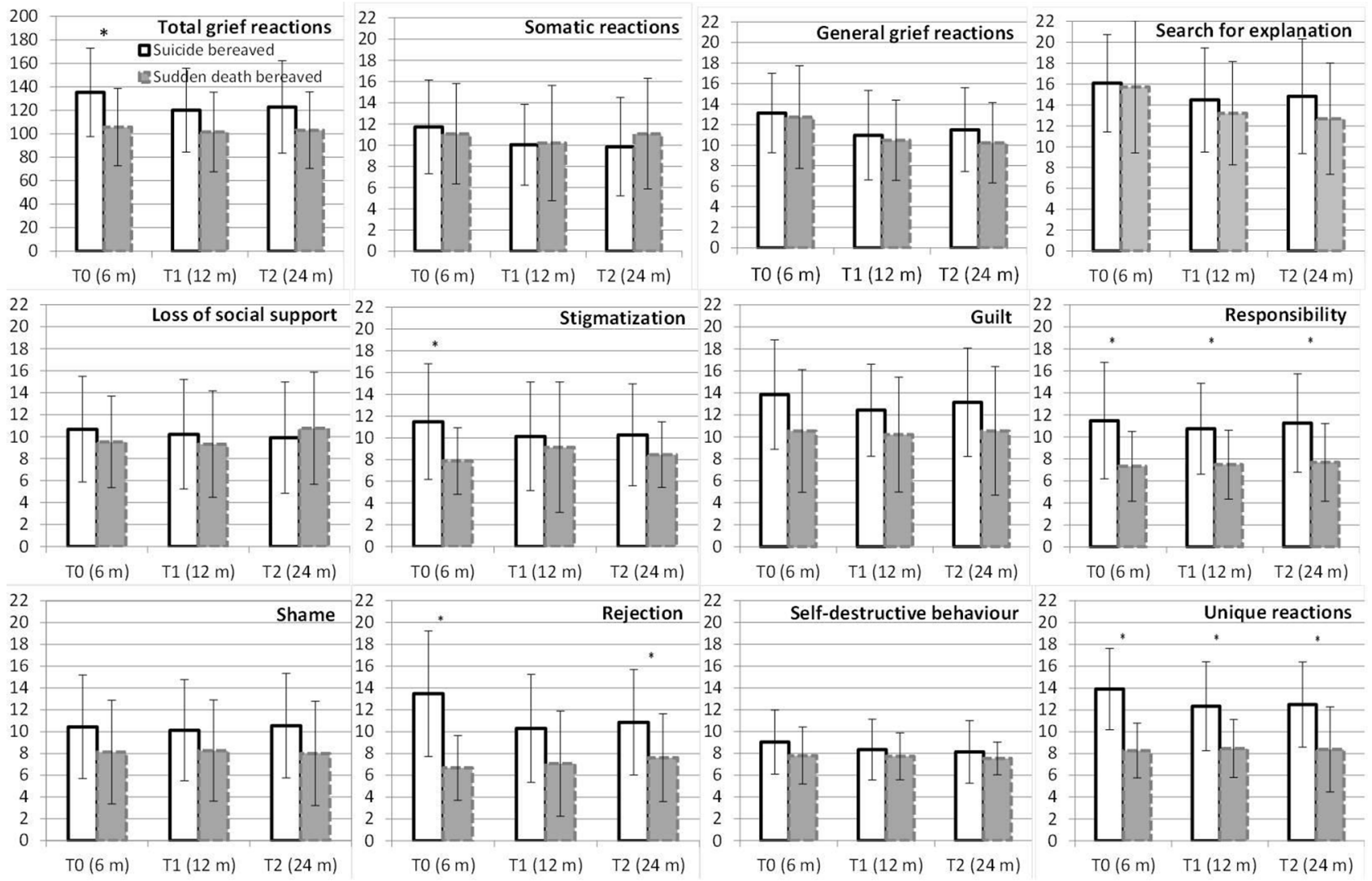

Figure 2 Grief reactions by the Grief Experience Questionnaire at 6 (T0), 12 (T1) and 24 months (T2). *P value <0.05 by the t-test between suicide and sudden-death group. m, months.

scores between 5 and 25 . The total score is the sum of all 55 items. Additional measures included demographic information, history of suicidal behaviour/ideation (including suicidal behaviour in family members and friends), Depression Anxiety Stress Scale 21 (DASS21) ${ }^{17}$ Bille-Brahe Social Support Scale, ${ }^{18}$ Brief COPE ${ }^{19}$ the WHO Quality of Life Australian version ${ }^{20}$ and questions about help seeking and its sources. The following information about the deceased was gathered: sociodemographic information (gender and age), circumstances of death (death location and method), and history of psychiatric problems and hospitalisation. The follow-up interview included the GEQ, DASS-21, Bille-Brahe Social Support Scale and the WHO Quality of Life Australian Version Scale, with additional items regarding the participants' recovery from distress, intercurrent life events using the Life Event Checklist ${ }^{21}$ and bereaved persons' perceptions of the experience.

The literature provides different opinions with regard to the appropriate sample size for the pilot studies. Nevertheless, the rule of thumb of 12 participants per group has been recommended in continuous variables, ${ }^{22}{ }^{23}$ with some authors suggesting that it could be based on pragmatics. ${ }^{11} 12$ The sample of the current pilot study included 25 suicide-bereaved and 15 sudden-death-bereaved persons, which was based on pragmatic reasons (such as limited time and resources) and exceeded the rule of thumb 12 for both groups. Participants were recruited in 2012, and follow-ups lasted until 2015. In the suddendeath group, eight people lost their loved ones to diseases of the circulatory system (mainly myocardial infarction) and seven to other external causes of death (mainly road accidents).

All participants gave a written consent to participate in the study.

\section{Statistical analysis}

Descriptive statistics including means and SD were calculated, and t-tests were used to compare the two bereavement groups at each time point. The Fisher's exact test was used to compare the demographic characteristics of suicide and sudden-death groups. In addition, linear mixed modelling for repeated measures was applied; fixed effects of group (suicide vs sudden death), time (T0, T1, T2) and interaction of group $\times$ time were estimated. The mixed model controls for non-independence among the repeated observations for each individual, and it does not drop out cases with missing values. A probability level of 0.05 was employed for all statistical tests. SPSS V.23.0 was used for data analyses.

\section{RESULTS}

\section{Characteristics}

There were no significant differences between the suicide-bereaved and sudden-death-bereaved people 
either by their own age ( 51.3 vs 53.5 years) and gender $(28 \%$ vs $20 \%$ males, $\mathrm{P}$ (Fisher's) $=0.715$ ), or by the deceased's gender $(72 \%$ vs $87 \%$ males, P (Fisher's $)=0.440$ ) and age (40 vs 46.7 years). In both groups, the bereaved persons were most frequently spouses $(36 \%$ vs $53.3 \%, \mathrm{P}=0.283)$ followed by mothers (32\% vs $20 \%$, $\mathrm{P}$ (Fisher's) $=0.486)$ and fathers $(20 \%$ vs $13.3 \%$, P (Fisher's) $=0.691)$. There was one son in each group, and there was a daughter-in-law and a cousin in suicide group and an ex-spouse in sudden-death group.

\section{Feasibility}

The main indicators to check the feasibility of a larger study were the process of recruitment (described under the Methods section), response and retention rates and questionnaire design. The response rate was $52.1 \%$ in the suicide-bereaved group and $45.5 \%$ in the sudden-death group. The main reasons for not participating were that relatives were not interested or were not contactable. In order to improve participation in the sudden-death group, we decided to change the title of the project from 'Suicide bereavement: Survivors in Australia' to 'Bereavement of suicide and sudden death' to minimise the potential impression that the study is only about suicide bereavement. There was a relatively small number of dropouts-two suicide-bereaved persons withdrew at 12 months and one at 24 months, with a final retention rate of $88 \%$. There were no dropouts in the suddendeath group at 12 months, but there were two dropouts at 24 months (one withdrew and one died from natural causes), retention rate $86.7 \%$. The questionnaire design was considered as adequate by the research team based on the feedback from the first interviews-the participants felt that the questionnaire covered relevant topics and was of adequate length. The analysis of the primary instrument is presented below.

\section{GEQ and grief reactions}

Cronbach's alphas ranged between 0.57 for self-destructive behaviour and 0.90 for rejection, with the total grief score alpha of 0.96. The highest scores throughout different time points were measured for 'search for explanation' for both groups, followed by 'unique reactions' and 'guilt' for suicide bereaved and by 'general grief reactions' and 'somatic reactions' for sudden-death bereaved (figure 2).

Linear mixed modelling for repeated measures showed a significant group effect (higher in suicide compared with sudden-death bereaved) for total grief reactions $(\mathrm{F}=4.21, \mathrm{P}=0.047)$, responsibility $(\mathrm{F}=9.30, \mathrm{P}=0.004)$, rejection $(\mathrm{F}=10.14, \mathrm{P}=0.003)$ and unique reactions $(\mathrm{F}=19.27, \mathrm{P}<0.001)$. Significant time effect (reduction) was measured for total grief reactions $(\mathrm{F}=4.73, \mathrm{P}=0.012)$, somatic reactions $(\mathrm{F}=4.35, \mathrm{P}=0.017)$, general grief reactions $(\mathrm{F}=12.06, \mathrm{P}<0.001)$ and search for explanation $(\mathrm{F}=6.32, \mathrm{P}=0.003)$. With regard to the time effect, it is important to note that pairwise comparison did not show any significant variation between time points T2 and T3. Only one significant time and group interaction was measured, rejection which showed a decline in suicide bereaved and an increase in sudden death group ( $F=4.95$, $\mathrm{P}=0.010$ ). Figure 2 also presents significant differences between suicides and sudden deaths in specific time points using t-test. The suicide bereaved had significantly higher levels of responsibility $(\mathrm{T} 0: \mathrm{t}=3.10, \mathrm{P}=0.004$; $\mathrm{T} 1: \mathrm{t}=2.77, \mathrm{P}=0.009$; $\mathrm{T} 2: \mathrm{t}=2.46, \mathrm{P}=0.019)$, unique reactions for all time points $(\mathrm{T} 0: \mathrm{t}=5.20, \mathrm{P}<0.001 ; \mathrm{T} 1: \mathrm{t}=3.55$, $\mathrm{P}=0.001$; T2: $\mathrm{t}=3.01, \mathrm{P}=0.005)$; rejection for $\mathrm{T} 0 \quad \mathrm{t}=4.94$, $\mathrm{P}<0.001)$ and $\mathrm{T} 1 \quad(\mathrm{t}=2.03, \mathrm{P}=0.050)$; and stigmatisation $(\mathrm{t}=2.40, \mathrm{P}=0.022)$ and total grief reactions $(\mathrm{t}=2.52$, $\mathrm{P}=0.016)$ at $\mathrm{T} 1$.

\section{DISCUSSION}

\section{Principal findings}

Overall, there is a lack of surveys comparing different types of grief; furthermore, a very limited number of studies have analysed suicide bereavement changes over time. ${ }^{91024}$ The importance of measuring changes longitudinally over time, rather than conducting registry-based linkage studies, lie in their ability to collect self-report measures about grief and social functioning. Furthermore, register-based linkage studies are in their infancy in Australia. As the first step in planning a full-scale study, we conducted a pilot study. Although there are inconsistencies around the definitions and differences between feasibility and pilot studies, the main purpose of the current pilot study was to test the feasibility of the study methodology and to present the preliminary findings of the main outcome measures - grief reactions measured with the GEQ.

The pilot study showed the suitability of the questionnaire and relatively smooth procedures for recruitment. The response rates were not ideal; $52.1 \%$ for suicide and $45.5 \%$ for sudden-death bereaved, which is comparable with our earlier psychological autopsy study. ${ }^{25}$ However, our response rate was higher compared with a historical US longitudinal study, where the response rate was only $35 \%$ for suicide and $30 \%$ for natural-death bereaved. ${ }^{8}$ While a Slovenian longitudinal study showed higher response rates of $68.3 \%$ and $55.1 \%$, our retention rates over $85 \%$ over 18 months (6-24 months after the death) compared favourably. ${ }^{24}$

To our knowledge, this is the first study to use non-convenience sample to measure time and group effect on suicide and sudden-death bereavement using the GEQ. ${ }^{16}$ The measure showed a sufficient sensitivity to capture differences between the groups over time. The results of our pilot study show that significantly higher levels of rejection, unique reactions, responsibility and total grief score in suicide-bereaved people compared with sudden-death bereaved remain significant over time. Previous studies have also found significantly higher levels of these reactions ${ }^{4-6}$; however, these studies were not longitudinal. Nevertheless, stigmatisation, which has shown to be higher in some studies, ${ }^{26}{ }^{27}$ was significantly higher in the suicide bereaved compared with sudden-death bereaved, 6 months after death, but not at 12 and 24 months. 
A significant decline in the total grief score measured with GEQ, especially between 6 and 12 months, is comparable with the Dutch study of a mixed sample of close suicide-bereaved relatives. ${ }^{9}$ The Dutch study showed a decline in complicated grief through the Dutch version of the Inventory of Traumatic Grief (ITG), between 2.5 and 13 months. ${ }^{8}$ Our results contradict a historical study of older spouses bereaved by suicide and natural death in the USA, which observed no change in Texas Inventory of Grief (TIG) at 2, 6 and 12 months after suicide; however, there was a decline between 12 and 30 months in both groups. ${ }^{8}$ It should be noted that these studies used different scales, with TIG including only 8 items $^{28}$ and ITG 10 items. ${ }^{29}$ As opposed to TIG and ITG, use of the GEQ in our study has enabled us to observe changes in 11 specific grief reactions which are measured through 55 items. Our findings indicate that some of the grief reactions, especially those considered to be common reactions for all types of bereavement (such as general grief reactions and somatic reactions), ${ }^{5} 16$ have decreased significantly with time. More specific analysis between the three time points indicated that changes between 6 and 12 months after death were significant; however, changes in the second year (between 12 and 24 months) were not significant. In addition, 'search for explanation' showed a significant decrease over time. Other reactions did not present significant changes and some items did not show any change over 2 years.

\section{Strengths and limitations}

The strengths of the study include prospective longitudinal design and systematic recruitment using the information obtained from police forms (through the QSR and Office of State Coroner). This study has a number of limitations. The sample size was small but was considered adequate for a pilot study. A large-scale study (currently under way) would enable more rigorous statistical modelling, including confounding factors such as gender, age, kinship type, mental health disorders, history of suicidal behaviour/ideation, social support, coping, helpseeking, circumstances of death and psychopathology. Response rates and retention rate were comparable with earlier studies of a similar nature. Extending the follow-up time over 24 months could add value to the study. It was not feasible to include people bereaved by natural causes of death as the 'reportable deaths' to the Australian Corners need to be sudden in their nature. ${ }^{30}$ Nevertheless, our pilot study showed the technical and administrative feasibility, and adequacy of the questionnaire.

\section{CONCLUSION}

A full study will provide further understanding of the differences in changes in grief reactions of people bereaved by suicide and those from sudden death and enable adjusting for confounding factors. This would help clinicians in treating and helping bereaved people, as well as in designing postvention services.

Acknowledgements We would like to acknowledge clinical interviewers Katie Sillar and Trudi Little. We would like to recognise Queensland Department of Justice, Office of State Coroner (OSC) for help with the recruitment. We would also like to acknowledge Dr Victoria Ross for her thorough linguistic revision of the manuscript.

Contributors KK and DdL designed the study, received funding and supervised data collection. KK conducted data analysis and drafted the manuscript. DdL provided feedback to the manuscript. Both authors contributed to the final version.

Funding This study was supported by the Griffith University Encouragement Grant and the Australian Research Council Discovery Grant "Bereavement of suicide and sudden death" (ARC DP140102567).

Competing interests None declared.

Patient consent Obtained.

Ethics approval Griffith University's Human Research Ethics Committee (CSR/04/11/HREC).

Provenance and peer review Not commissioned; externally peer reviewed.

Data sharing statement Deidentified data collected in the frames of the study can be made available on request to other researchers after full-scale study and the reporting period is finished.

Open Access This is an Open Access article distributed in accordance with the Creative Commons Attribution Non Commercial (CC BY-NC 4.0) license, which permits others to distribute, remix, adapt, build upon this work non-commercially, and license their derivative works on different terms, provided the original work is properly cited and the use is non-commercial. See: http://creativecommons.org/ licenses/by-nc/4.0/

(C) Article author(s) (or their employer(s) unless otherwise stated in the text of the article) 2018. All rights reserved. No commercial use is permitted unless otherwise expressly granted.

\section{REFERENCES}

1. Berman AL. Estimating the population of survivors of suicide: seeking an evidence base. Suicide Life Threat Behav 2011;41:110-6.

2. Cerel J, McIntosh JL, Neimeyer RA, et al. The continuum of "survivorship": definitional issues in the aftermath of suicide. Suicide Life Threat Behav 2014;44:591-600.

3. Andriessen K, Rahman B, Draper B, et al. Prevalence of exposure to suicide: a meta-analysis of population-based studies. J Psychiatr Res 2017;88:113-20.

4. Pitman A, Osborn D, King M, et al. Effects of suicide bereavement on mental health and suicide risk. Lancet Psychiatry 2014;1:86-94.

5. Sveen CA, Walby FA. Suicide survivors' mental health and grief reactions: a systematic review of controlled studies. Suicide Life Threat Behav 2008;38:13-29.

6. Kolves K, De Leo D. Is suicide grief different? Empirical evidence. In: De Leo D, Cimitan A, Dyregrov K, Grad O, Andriessen K, eds. Bereavement after traumatic death: Helping the survivors. Göttingen: Hogrefe \& Huber, 2014:161-73.

7. Cerel J, Fristad MA, Weller EB, et al. Suicide-bereaved children and adolescents: a controlled longitudinal examination. J Am Acad Child Adolesc Psychiatry 1999;38:672-9.

8. Farberow NL, Gallagher-thompson D, Gilewski M, et al. Changes in grief and mental health of bereaved spouses of older suicides. J Gerontol 1992;47:P357-66.

9. de Groot M, Kollen BJ. Course of bereavement over 8-10 years in first degree relatives and spouses of people who committed suicide: longitudinal community based cohort study. BMJ 2013;347:f5519.

10. Erlangsen A, Runeson B, Bolton JM, et al. Association between spousal suicide and mental, physical, and social health outcomes: a longitudinal and nationwide register-based study. JAMA Psychiatry 2017;74:456-64.

11. Thabane L, Ma J, Chu R, et al. A tutorial on pilot studies: the what, why and how. BMC Med Res Methodol 2010;10:1.

12. Leon AC, Davis LL, Kraemer HC. The role and interpretation of pilot studies in clinical research. J Psychiatr Res 2011;45:626-9.

13. Arain M, Campbell MJ, Cooper CL, et al. What is a pilot or feasibility study? A review of current practice and editorial policy. BMC Med Res Methodol 2010;10:67. 
14. World Health Organization. International statistical classification of diseases and health related problems. 10th revision. Geneva: WHO. 1992.

15. Murai T, Baba M, Ro A, et al. Sudden death due to cardiovascular disorders: a review of the studies on the medico-legal cases in Tokyo. Keio J Med 2001;50:175-81.

16. Barrett TW, Scott TB. Development of the grief experience questionnaire. Suicide Life Threat Behav 1989;19:201-15.

17. Lovibond SH, Lovibond PF. Manual for the depression anxiety stress scales. Sydney: Psychology Foundation, 1995

18. Bille-Brahe $U$, Jensen $B$. The importance of social support. In: De Leo D, Bille-Brahe U, Kerkhof A, Schmidtke A, eds. Suicidal behaviour: theories and research findings. Göttingen: Hogrefe \& Huber, 2004:187-208.

19. Carver CS. You want to measure coping but your protocol's too long: consider the brief Cope. Int J Behav Med 1997:4:92-100.

20. Murphy B, Herrman H, Hawthorne G, et al. Australian WHOQoL instruments: user's manual and interpretation guide. Australian WHOQoL Melbourne: Field Study Centre, 2000.

21. Brand AH, Johnson JH. Note on reliability of the Life Events Checklist. Psychol Rep 1982;50:1274.

22. Julious SA. Sample size of 12 per group rule of thumb for a pilot study. Pharm Stat 2005;4:287-91.

23. van Belle G. Statistical Rules of Thumb. New York: John Wiley and Sons, 2002.
24. Grad OT, Zavasnik A. Phenomenology of bereavement process after suicide, traffic accident and terminal illness (in spouses). Arch Suicide Res 1999;5:157-72.

25. Ross V, Kõlves K, De Leo D. Beyond psychopathology: a casecontrol psychological autopsy study of young adult males. Int J Soc Psychiatry 2017;63:151-60.

26. Harwood D, Hawton K, Hope T, et al. The grief experiences and needs of bereaved relatives and friends of older people dying through suicide: a descriptive and case-control study. J Affect Disord 2002;72:185-94.

27. Bailley SE, Kral MJ, Dunham K. Survivors of suicide do grieve differently: empirical support for a common sense proposition. Suicide Life Threat Behav 1999;29:256-71.

28. Faschingbauer TR, Devaul RA, Zisook S. Development of the texas inventory of grief. Am J Psychiatry 1977;134:696-8.

29. Prigerson HG, Jacobs SC. Diagnostic criteria for traumatic grief: A rationale, consensus criteria, and preliminary empirical test. In: Stroebe MS, Hansson RO, Stroebe W, Schut H, eds. Handbook of bereavement research. Washington, DC: American Psychological Association, 2001:614-46.

30. Queensland Government. Coroners Act. 2003 https://www. legislation.qld.gov.au/view/pdf/inforce/current/act-2003-013 (accessed 10 Nov 2017). 